\title{
METODE K-NEAREST NEIGHBOR UNTUK PERAMALAN KEPADATAN ARUS LALU LINTAS DI GERBANG TOL MANYARAN SEMARANG
}

Maslikhatus Sho'imah*, Rony Wijanarko dan Nugroho Eko Budiyanto

Program Studi Teknik Informatika Fakultas Teknik Universitas Wahid Hasyim

Jl. Menoreh Tengah X/22 Sampangan Semarang 50236

*Email: maslikhatus@gmail.com

\begin{abstract}
Abstrak
Lalu lintas memiliki peran yang sangat penting di dalam kehidupan bermasyarakat. Dalam berlalu lintas juga sering muncul masalah dalam kegiatan berlalu lintas, diantaranya adalah kemacetan dan kecelekaan yang disebabkan oleh banyak faktor, salah satu faktor penyebabnya adalah jumlah kendaraan yang melebihi kapasitas jalan. Banyak penelitian yang dilakukan dalam memprediksi arus lalu lintas dengan menggunakan banyak metode seperti Particle Swarm Optimization (Pso), Neurak Netwrok dan masih banyak lagi. Dalam penelitian ini metode yang di gunakan adalah $K$-nearest neighbor $(K-N N)$ yang mempunyai tingkat akurasi yang cukup tinggi. Salah satu kelemahan dari metode $K-N N$ adalah menggunakan seluruh data training dalam menjalankan klasifikasi yang mengakibatkan pada lamanya saat menjalankan prediksi dan mengurangi tingkat akurasi. Dalam penelitian ini menggunakan metode $K-N N$ dengan tujuan menghasilkan nilai prediksi jumlah kendaraan yang melewati gerbang tol Manyaran pada tahun 2018 dengan jumlah prediksi angka kendaraan pada bulan Januari 949014 Februari 902284, Maret 845307, April 919796, Mei 970834, Juni 1377159, Juli 946759, Agustus 897521, September 939153, Oktober 921456, November 931507, Desember 946750 .
\end{abstract}

Kata Kunci : peramalan, $k$-nearest neighbor, data training, particle swarm optimization, neurak netwrok

\section{PENDAHULUAN}

Lalu lintas memiliki peranan yang sangat penting bagi kehidupan bermasyarakat sehari-hari. Adapun beberapa masalah yang kadang muncul dalam proses berlalu lintas adalah kemacetan yang bisa di sebabkan oleh banyak faktor, salah satu penyebab terjadinya kemacetan adalah jumlah kendaraan yang memadati lalu lintas.

Jumlah kendaraan yang melewati gerbang tol Manyaran pada bulan Januari tahun 2010 sampai dengan Desember 2017 mayoritas adalah kendaraan ringan. Data ini didapatkan dari Dinas Jasa Marga kota semarang dari bulan Januari 2010 sampai dengan Desember 2017.

Data time series adalah himpunan data yang tercatat secara periodik. Seperti himpunan data harian, mingguan, bulanan, atau tahunan. Prediksi data time series dapat digunakan untuk memprediksi jalur lalu lintas dengan menggunakan data yang sudah ada dengan menggunakan perhitungan matematika dan statistika. Jumlah data kendaraan yang masuk ke gerbang tol Manyaran bulan Januari 2010 sampai Desember 2017 adalah jenis time series yang penghitungannya bersifat bulanan karena pola data yang di gunakan berulang pada kurun waktu tertentu pada bulan Januari 2010 sampai Desember 2017. Dalam penghitungan ini menggunakan algoritma K-nearest neighbor (K-NN) karena nilai akurasi yang di hasilkan lebih tinggi di bandingkan dengan algoritma yang lain, dengan tujuan pencarian nilai prediksi jumlah kendaran yang melewati gerbang tol Manyaran Semarang pada tahun berikutnya yaitu tahun 2018

\section{Tujuan Penelitian}

Tujuan dari penelitian yang dilakukan adalah untuk memperoleh nilai prediksi jumlah kendaran yang melewati gerbang tol Manyaran Semarang pada tahun 2018 dalam memprediksikan arus lalu lintas jangka pendek di gerbang Tol Manyaran dengan menggunakan metode $K$-nearest neighbor (K-NN).

\section{Manfaat Penelitian}


Adapun manfaat dari penelitian ini adalah:

1. Memberikan kemudahan bagi petugas dinas jasa marga untuk mengetahui prediksi arus lalu lintas terutama yang melewati gerbang tol Manyaran Semarang.

2. Menggetahui model perhitungan arus lalu lintas dalam mempredikdi arus lalu lintas yang akan datang.

3. Memberikan sedikit penjelasan tentang metode yang di gunakan.

\section{Kajian Pustaka \\ Tinjauan Pustaka}

Penelitian ini dilakukan untuk meningkatkan akurasi dari penelitian sebelumnya dalam memprediksi arus lalu lintas jangka pendek di jalan Semarang Bawen. Penelitian sebelumnya menggunakan Neural Netwrok dengan Genetic Algoritm yang menghasikan RMSE sebesar 106,16 dan pada penelitian ini menggunakan Algoritma Neural Network dan Particle Swarm Optimization menghasilkan RMSE yang lebih rendah yaitu 55, 41. Ini menunjukkan kinerja Neural Network dan PSO lebih baik dibandingkan Neural Network dengan GA ( Erisa, 2015)

\section{K-nearest Neighbor}

Algoritma K-nearest neighbor (KNN) merupakan sebuah metode untuk melakukan klasifikasi terhadap objek berdasarkan data terdekat dari objek tersebut, K-NN juga merupakan algoritma supervised learning dimana hasil klasifikasi data baru berdasarkan pada kategori sebagian besar jarak terdekat menuju K. Klasifikasi dilakukan tanpa memanfaatkan model tetapi berdasarkan memori.(ida fitroh, 2015)

Algoritma ini menghitung berdasarkan jarak minimum dari data baru ke $\mathrm{K}$ terdekat yang sudah ditetapkan. Jarak antara data baru dengan data learning dihitung dengan cara mengukur jarak antara titik yang mewakili data baru dengan titik yang mewakili data learning dengan rumus Euclidean Distance.

$\mathrm{D}(\mathrm{P}-\mathrm{Q})=\sqrt{\sum_{j=1}^{n}\left(p_{i}-q_{i}\right)^{2}}$

Keterengan:

$\mathrm{D}(\mathrm{P}-\mathrm{Q})=$ Eucludian distance

$p_{i}=$ data latih atau data training

$q_{i}=$ data baru atau data testing

Cara kerja algoritma KNN:

1. Menentukan jumlah $\mathrm{K}=$ jumlah tetangga terdekat

2. Menghitung jarak antara data baru dengan semua data training

3. Menggurutkan data tersebut dan menetapkan tetengga terdekat berdasarkan jarak minimum ke-K

4. Memeriksa kelas dari jarak terdekat

5. Menggunakan mayoritas sederhana dari kelas tetangga terdekat sebagai nilai prediksi data baru

\section{RMSE}

RMSE adalah parameter yang digunakan untuk mengukur keutamaan model setelah diperoleh suatu model. RMSE adalah alat pemilihan model berdasarkan pada kesalahan hasil perkiraan. Nilai kesalahan yang muncul menunjukkan seberapa besar perbedaan hasil perkiraan dengan nilai yang akan diperkirakan. RMSE dikenal sebagai standar dari error dari regresi dan didefisnikan sebagai:

$\mathrm{RMSE}=\sqrt{\frac{\sum_{i=1}^{n}\left(Y_{i}-Y_{i+1}\right)^{2}}{n}}$

Keterangan :

$\mathrm{Y}_{\mathrm{i}} \quad=$ Nilai data

$\mathrm{Y}_{\mathrm{i}+1}=$ Nilai Waktu/ Tempat

$n$ = Banyaknya Observasi

\section{Normalisasi Database}

Proses normalisasi adalah proses pengelompokan data elemen menjadi tabeltabel yang menunjukkan entity dan relasinya. Dalam proses normalisasi akan diuji dari beberapa kondisi, apakah terdapat kesulitas padasaat menambah / insert, menghapus / delet, menghapus / update, dan membaca / retrieve pada suatu 
database. Jika terdapat kesulitan pada pengujian tersebut maka relasinya akan dipecah menjadi beberapa tabel lagi, sehingga diperoleh database yang optimal, sedangkan tujuan dari normalisasi sendiri adalah supaya data yang ada memiliki data interrity yang kuat sehingga kketika kita melakukan relasi antara tabel akan lebih mudah menjaga data intergrity, selainitu normalisasi juga digunakan untuk mengeliminasi anomaly.

\section{Rapid Miner}

Rapid miner adalah suatu software yang digunakan untuk mengolah data mining, yang dilakukan oleh rapid miner adalah tentang analisis teks, mengekstrak pola-pola data set yang besar dan mengkombinasikannya dengan mengunakan metode statistika, kecerdasan buatan dan juga database. Tujuan dari analisis teks sendiri adalah untuk pemperoleh informasi yang bekualitas tinggi dari data yang sedang diolah.

\section{METODE}

\section{Metode Pengembangan Sistem}

Dalam penelitian ini menggunakan perangkat Microsoft Excel untuk pengolahan dataset, dan Rapid Miner untuk memudahkan proses pengujian dengan mengolah berbagai parameter dengan menggunakan metode $K$-Nearest Neighbor .

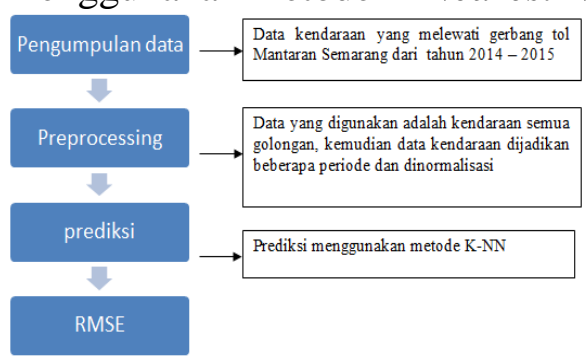

HASIL DAN PEMBAHASAN

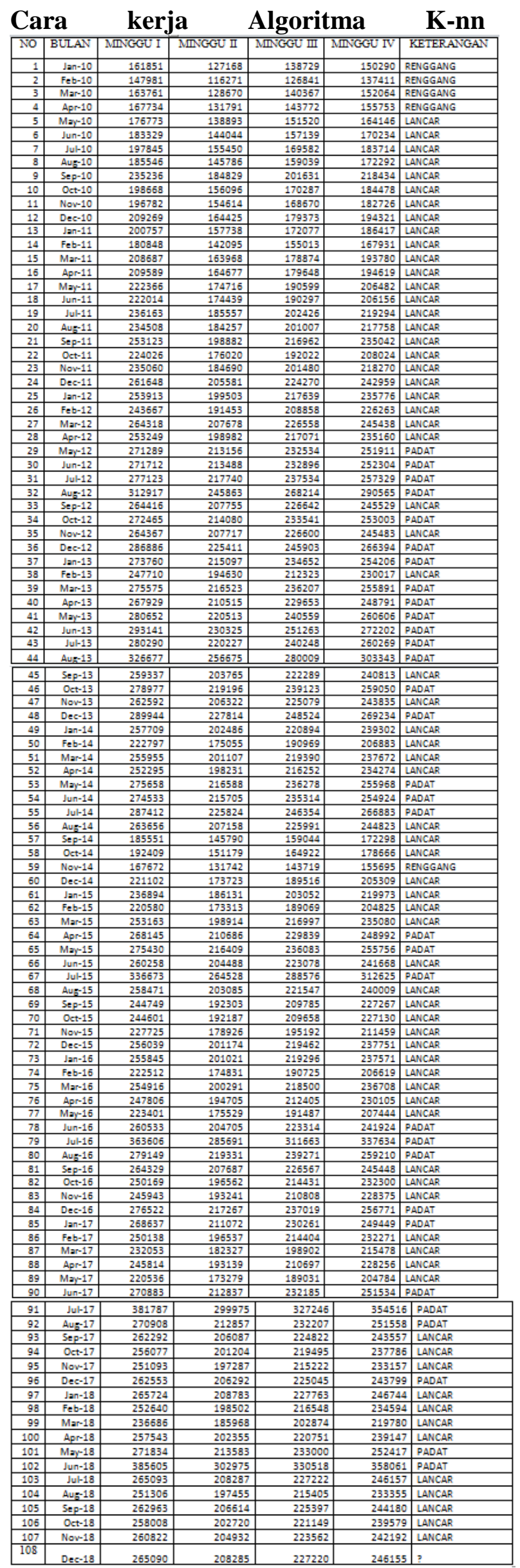


Menentukan nilak K, K=17

Hitung Distance menggunakan ecludian distance

\begin{tabular}{|c|c|c|c|c|c|}
\hline No & BULAN & DISNTANCE & & & \\
\hline 1 & $D 108, D 1$ & 185092 & 45 & D.108,045 & 10314,51 \\
\hline 2 & D198, D2 & 209957,3 & 46 & $D 108,046$ & 24896,99 \\
\hline 3 & $\mathrm{D} 108,03$ & 181666,3 & 47 & D108, D47 & 4478,81 \\
\hline 4 & D.108. D4 & 174544,5 & 48 & D108.048 & 44560,18 \\
\hline 5 & D108,05 & 158338,6 & 49 & D108,049 & 13232,11 \\
\hline 6 & D198,D6 & 146585,4 & 50 & D108,050 & 75824,49 \\
\hline 7 & D.108, D7 & 120558,9 & 51 & D108,051 & 16378,12 \\
\hline 8 & D108,D8 & 142610,5 & 52 & D108,052 & 22940,21 \\
\hline 9 & $D 108,09$ & 53522,82 & 53 & D.108,053 & 18946,33 \\
\hline 10 & $D 108, D 10$ & 119084 & 54 & D.108.054 & 16929,82 \\
\hline 11 & D108,D11 & 122465,4 & 55 & D.108,055 & 40020,63 \\
\hline 12 & $D 108, D 12$ & 100078,9 & 56 & D.108,056 & 2571,22 \\
\hline 13 & $\mathrm{D} 103,013$ & 115339,1 & 57 & D.108,057 & 142600,5 \\
\hline 14 & $D 103, D 14$ & 151032 & 58 & D.108,058 & 130305,1 \\
\hline 15 & $D 108,015$ & 101122,6 & 59 & D108,059 & 174655,5 \\
\hline 16 & $D 108,016$ & 99504,14 & 60 & D108.060 & 78864,08 \\
\hline 17 & $D 108,017$ & $\begin{array}{l}9950,14 \\
76598,07 \\
\end{array}$ & $\frac{61}{62}$ & D108,061 & $\begin{array}{r}50551,5 \\
7070.70\end{array}$ \\
\hline 18 & D108,D18 & 77229,08 & 62 & D108,062 & 79798,79 \\
\hline 19 & D108,D19 & 51861.21 & 63 & D.108,D63 & 21383,52 \\
\hline 20 & D108,D20 & & 64 & D.108,064 & 5477,78 \\
\hline 21 & & $\begin{array}{r}54828 \\
2145581 \\
\end{array}$ & 65 & D.108.065 & 18537,71 \\
\hline 22 & 0108.022 & 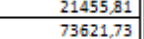 & $\frac{66}{67}$ & $\frac{D 108,066}{D 108}$ & $\begin{array}{r}8662,95 \\
1283353 \\
\end{array}$ \\
\hline 23 & $D 108,023$ & $\frac{75021,15}{53839,57}$ & 68 & D108.D68 & 11866,18 \\
\hline 24 & 0108,024 & 6170,54 & 69 & D108,D69 & 36468,5 \\
\hline 25 & D 108,025 & 20039,18 & 70 & $D 108,070$ & 36733,06 \\
\hline 26 & 0108,026 & 38407,21 & 71 & D.108,071 & 66990,36 \\
\hline 27 & $D 108,027$ & 1384,51 & 72 & D.108,072 & 16227,02 \\
\hline 28 & $D 108,028$ & 21228,41 & 73 & D198.073 & 16574,44 \\
\hline 29 & $D 108,029$ & 11114,19 & 74 & D108,074 & 76335,02 \\
\hline 30 & D108.030 & 11872,71 & $\frac{75}{76}$ & $\frac{D 108,075}{0108,075}$ & $\frac{18240,03}{3097,1}$ \\
\hline 31 & D108.D31 & 21573,28 & 76 & D108,076 & 30987,71 \\
\hline 32 & D108, D32 & 85745,44 & 77 & D108,077 & 74741,68 \\
\hline 33 & $D 108,033$ & 1208,81 & 78 & D108,078 & 8169,99 \\
\hline 34 & $D 108,034$ & 13222,07 & 79 & D108,079 & 176624,4 \\
\hline 35 & $D 108,035$ & 1296,66 & 80 & D.108,080 & 25205,7 \\
\hline 36 & $D 108,036$ & 39077,38 & 81 & D108,081 & 1364,81 \\
\hline 37 & $D 108,037$ & 15544,31 & 82 & D.108,082 & 26750,32 \\
\hline 38 & $D 108,038$ & 31158,89 & 83 & D.108,083 & 34328,42 \\
\hline 39 & D108,D39 & & 84 & D108,084 & 20496 \\
\hline 40 & & $\frac{1079,14}{5089,24}$ & 85 & D.108,085 & 6360,07 \\
\hline 41 & D108.D41 & $\begin{array}{r}5089,24 \\
27900,94\end{array}$ & 86 & D.108,086 & 26806,36 \\
\hline & $\frac{D 108, D 41}{D .108, D 42}$ & 27900,94 & 87 & D.103.087 & 59230,51 \\
\hline 43 & $\frac{D, 198,042}{D 108,043}$ & $\frac{50290,46}{27250,35}$ & 88 & Didesanos8 & $\frac{34559,41}{79877,61}$ \\
\hline 44 & $\frac{D 108,043}{D 108,044}$ & $\begin{array}{l}27250,35 \\
110415,5 \\
\end{array}$ & 89 & D.108.089 & 79877,61 \\
\hline & D108, D44 & 110415,5 & 90 & D108.D90 & 10385,8 \\
\hline 91 & D108,D91 & 209218,8 & & & \\
\hline 92 & D108, D92 & 10431,48 & & & \\
\hline 93 & D.108, D93 & 5015,94 & & & \\
\hline 94 & D108, D94 & 16158,25 & & & \\
\hline 95 & D108, D95 & 25095,28 & & & \\
\hline 96 & $D 108,096$ & 4548,59 & & & \\
\hline 97 & D108, D97 & 1136,4 & & & \\
\hline 98 & D108, D98 & 22321,77 & & & \\
\hline 99 & D108,099 & 50923,98 & & & \\
\hline 100 & D108,D100 & 13530,8 & & & \\
\hline 101 & D108, D101 & 12090,07 & & & \\
\hline 102 & D108, D102 & 216063,7 & & & \\
\hline 103 & D108,0103 & $\begin{array}{r}4,52 \\
\end{array}$ & & & \\
\hline 104 & D108, D104 & 24712,76 & & & \\
\hline 105 & D108, D105 & 3813,66 & & & \\
\hline 106 & D.108.0106 & 12697,49 & & & \\
\hline 107 & D108,D107 & 7651,77 & & & \\
\hline
\end{tabular}

Urutkan data berdasarkan jarak

\begin{tabular}{|c|c|c|c|}
\hline NO & BULAN & DISNTANCE & RANGKING \\
\hline 1 & $D_{1} 08, D 1$ & 235581.5 & 4 \\
\hline 2 & $\mathrm{D} 108,02$ & 260446,8 & 2 \\
\hline 3 & $D_{1} 08,03$ & 232155,9 & 5 \\
\hline 4 & D.108. D4 & 225034 & 8 \\
\hline 5 & D108, D5 & 208828,1 & 9 \\
\hline 6 & D108, D6 & 197074,9 & 11 \\
\hline 7 & D1.8B. 07 & 171048,4 & 17 \\
\hline 8 & D108,D8 & 193100,1 & 12 \\
\hline 9 & D.108.09 & 104012,3 & 38 \\
\hline 10 & $D 108,010$ & 169573,5 & 18 \\
\hline 11 & D108,D11 & 172955 & 16 \\
\hline 12 & $D 108, D 12$ & 150568,5 & 22 \\
\hline 13 & $D 103, D 13$ & 165828,6 & 19 \\
\hline 14 & D108,D14 & 201521,6 & 10 \\
\hline 15 & D108,D15 & 151612,1 & 21 \\
\hline 16 & $D 108, D 16$ & 149993,7 & 23 \\
\hline 17 & D108, D17 & 127087,6 & 29 \\
\hline 18 & D108,D18 & 127718,6 & 28 \\
\hline 19 & D108.019 & 102350,7 & 39 \\
\hline 20 & D108, D20 & 105317,5 & 36 \\
\hline 21 & D108.021 & 71945,33 & 64 \\
\hline 22 & 0108,022 & 124111,3 & 33 \\
\hline 23 & $D 103,023$ & 104329,1 & 37 \\
\hline 24 & 0108.024 & 56660,05 & 94 \\
\hline 25 & $D 108,025$ & 70528,7 & 68 \\
\hline 26 & D108, D26 & 88896,73 & 46 \\
\hline 27 & D103,027 & 51874,02 & 102 \\
\hline 28 & D108.028 & 71717,93 & 66 \\
\hline 29 & 0108,029 & 39375,33 & 86 \\
\hline 30 & $D 108, D 30$ & 38616,81 & 84 \\
\hline 31 & D108.031 & 28916,24 & 63 \\
\hline 32 & D101, D32 & 35255,92 & 24 \\
\hline 33 & D108.033 & 51698,33 & 105 \\
\hline 34 & D108.034 & 37267,45 & 81 \\
\hline 35 & D108,035 & 51786,17 & 104 \\
\hline 36 & D108.036 & 11412,14 & 45 \\
\hline 37 & D108.037 & 34945,21 & 78 \\
\hline 38 & 0108.038 & 81648,41 & 51 \\
\hline 39 & D103.D39 & 31691,78 & 70 \\
\hline 40 & D103,D40 & 45400,28 & 96 \\
\hline 41 & D108,D41 & 22588,58 & 53 \\
\hline 42 & $D 108, D 42$ & 199,06 & 42 \\
\hline 43 & $\mathrm{D} 108, \mathrm{D} 43$ & 23239,17 & 54 \\
\hline 44 & D108.D44 & 59926,01 & 20 \\
\hline 45 & $D 108, D 45$ & 60804,03 & 89 \\
\hline
\end{tabular}




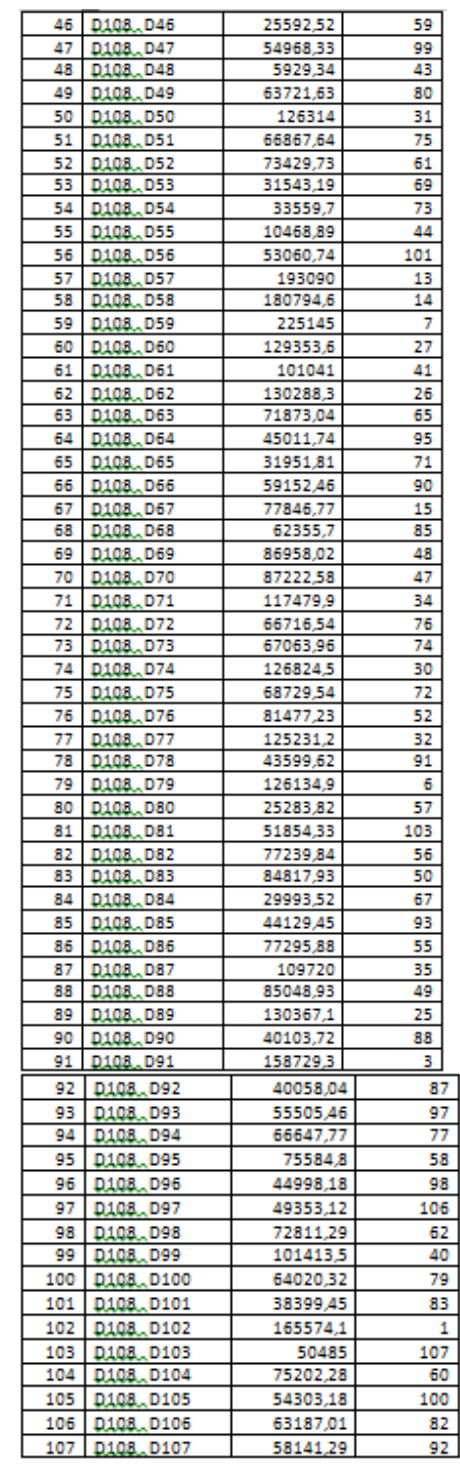

Tentukan k klasifikasi (k terbaik berdasarkan rangking)

\begin{tabular}{|c|c|c|c|}
\hline No & BULAN & DISNTANCE & RANGKING \\
\hline 102 & D101, D102 & 216063,7 & 1 \\
\hline 2 & $\mathrm{D} 10 \mathrm{~B}, \mathrm{D} 2$ & 209957,3 & 2 \\
\hline 91 & D108,D91 & 209218,8 & 3 \\
\hline 1 & $D 108, D 1$ & 185092 & 4 \\
\hline 3 & D108.03 & 181666,3 & 5 \\
\hline 79 & D108, D79 & 176624.4 & 6 \\
\hline 59 & D108,059 & 174655,5 & 7 \\
\hline 4 & D108. D4 & 174544,5 & 8 \\
\hline 5 & D.108,05 & 158338,6 & 9 \\
\hline 14 & D108, D14 & 151032 & 10 \\
\hline 6 & $D 108,06$ & 146585,4 & 11 \\
\hline 8 & D108,D8 & 142610,5 & 12 \\
\hline 57 & D108,057 & 142600,5 & 13 \\
\hline 58 & D108,058 & 130305,1 & 14 \\
\hline 67 & $D 108,067$ & 128336,3 & 15 \\
\hline 11 & D108,D11 & 122465,4 & 16 \\
\hline 7 & D108.07 & 120558,9 & 17 \\
\hline
\end{tabular}

\section{Tentukan klasifikasi menggunakan kategori mayoritas}

\begin{tabular}{|c|c|c|c|c|}
\hline NO & BULAN & DISNTANCE & RANGKING & KETERANGAN \\
\hline 102 & $\mathrm{D} 108, \mathrm{D} 102$ & 216063,7 & 1 & PADAT \\
\hline 2 & $0108 . D 2$ & 209957.3 & 2 & RENGGANG \\
\hline 91 & D108, D91 & 209218,8 & 3 & PADAT \\
\hline 1 & D108, D1 & 185092 & 4 & RENGGANG \\
\hline 3 & D108, D3 & 181666,3 & 5 & RENGGANG \\
\hline 79 & D108. 079 & 176624,4 & 6 & PADAT \\
\hline 59 & D108, D59 & 174655,5 & 7 & RENGGANG \\
\hline 4 & D108, D4 & 174544,5 & 8 & RENGGANG \\
\hline 5 & $\mathrm{D} 108, \mathrm{D} 5$ & 158338,6 & 9 & LANCAR \\
\hline 14 & D108, D14 & 151032 & 10 & LANCAR \\
\hline 6 & $\mathrm{D} 108, \mathrm{D} 6$ & 146585,4 & 11 & LANCAR \\
\hline 8 & D108, D8 & 142610,5 & 12 & LANCAR \\
\hline 57 & 0108,057 & 142600,5 & 13 & LANCAR \\
\hline 58 & 0108.058 & 130305,1 & 14 & LANCAR \\
\hline 67 & D108, D67 & 128336,3 & 15 & PADAT \\
\hline 11 & D108, D11 & 122465,4 & 16 & LANCAR \\
\hline 7 & 0108.07 & 120558.9 & 17 & LANCAR \\
\hline
\end{tabular}

Karena Mayoritas padat maka hasil klasifikasi Desember 2018 adalah LANCAR

\section{Pengolahan Data Menggunakan Rapidminer}

Data yang di masukan di rapidminer adalah data kendaraan yang melewati gerbang tol manyaran dari januari 2010 sampai desember 2017 dan data prediksi di tahun 2018. Kemudian data diubah menjadi 7 periode karena metode k-nn menggunakan data deret waktu, data akan di normalisasikan dengan cara membagi jumlah kendaraan dengan nilai 10000 supaya data yang diolah tidak terlalu besar dan mempengaruhi hasil prediksi dan mendapatkan nilai error yang lebih rendah 


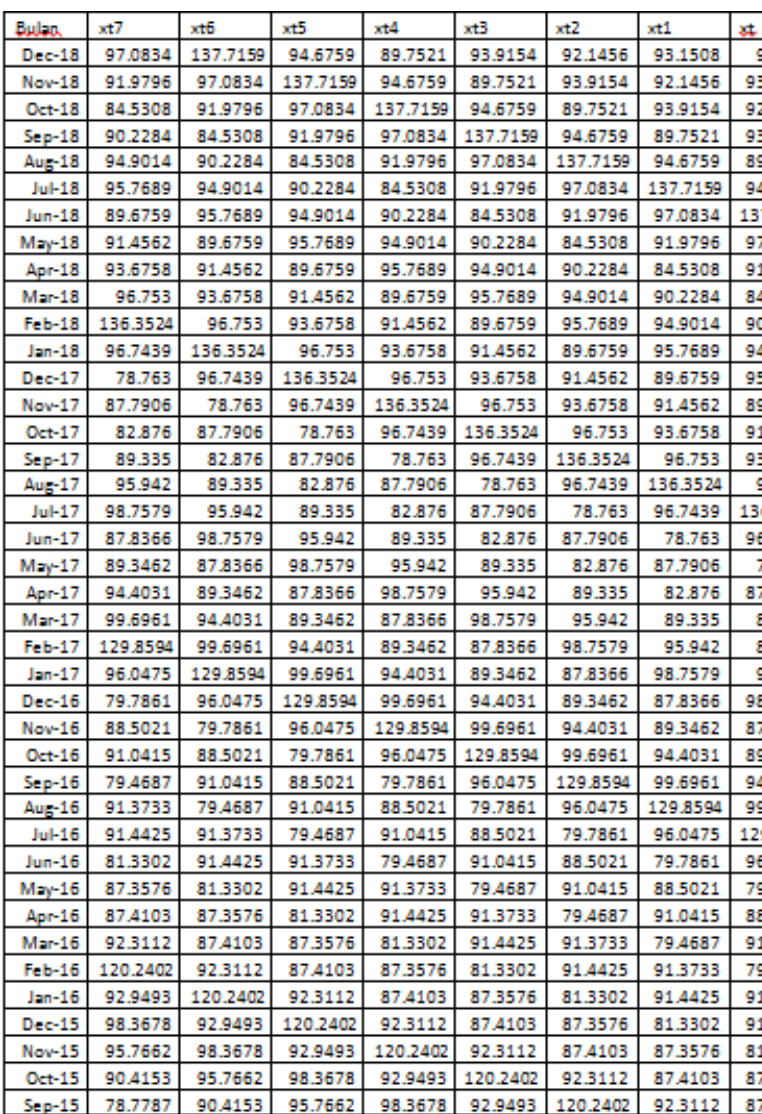

\subsection{Proses pada aplikasi rapidminer}

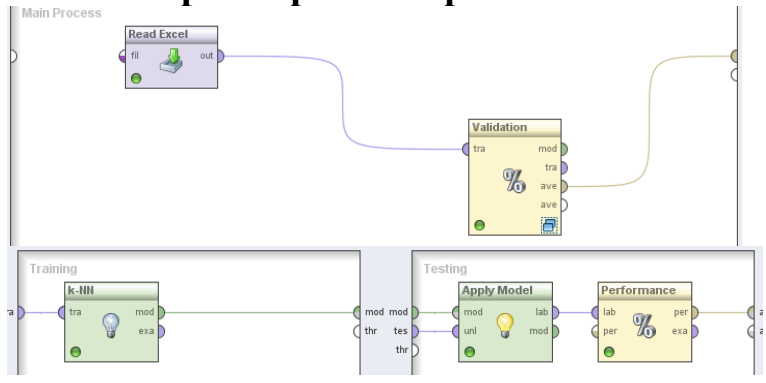

\section{Hasil Prediksi RMSE}

Metode yang digunakan dalam pengujian ini adalah metode K-NN. Dan data yang digunakan adalah data multivariat. Data tersebut adalah data kendaraan yang melewati Tol Manyaran yang telah di ubah menjadi data multivariate dari data sebelumnya adalah data univariat yang di dapat. Kemudian data dinormalisasikan menjadi beberapa periode yaitu 1 periode sampai dengan 7 periode sebelumnya. Masing-masing periode dipilih berdasarkan arsitektur terbaik yang menggunakan metode K-NN.

1 periode -7 periode

1 periode 2 periode 3 periode
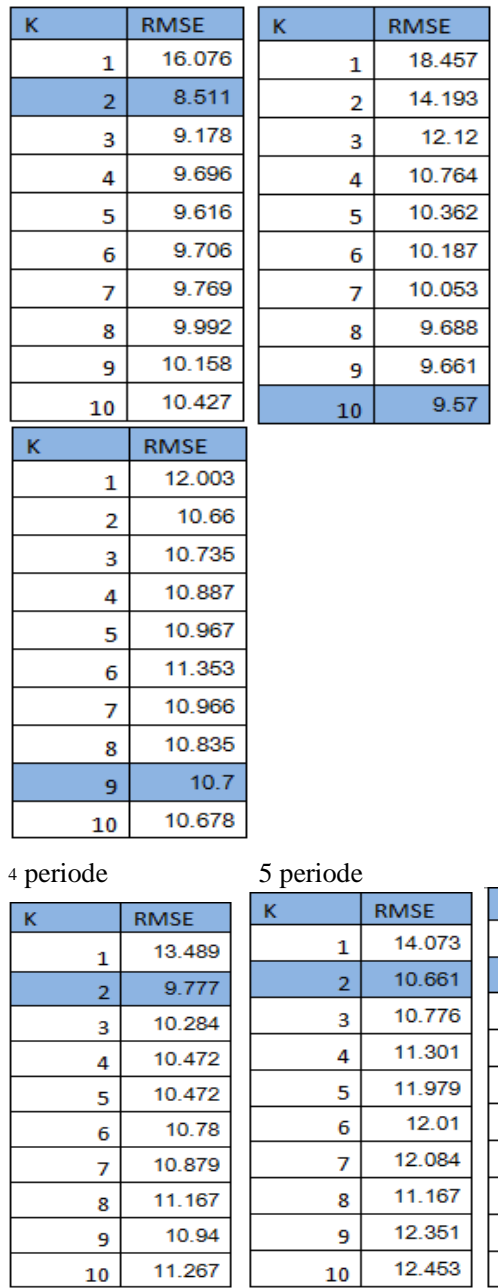

7 periode
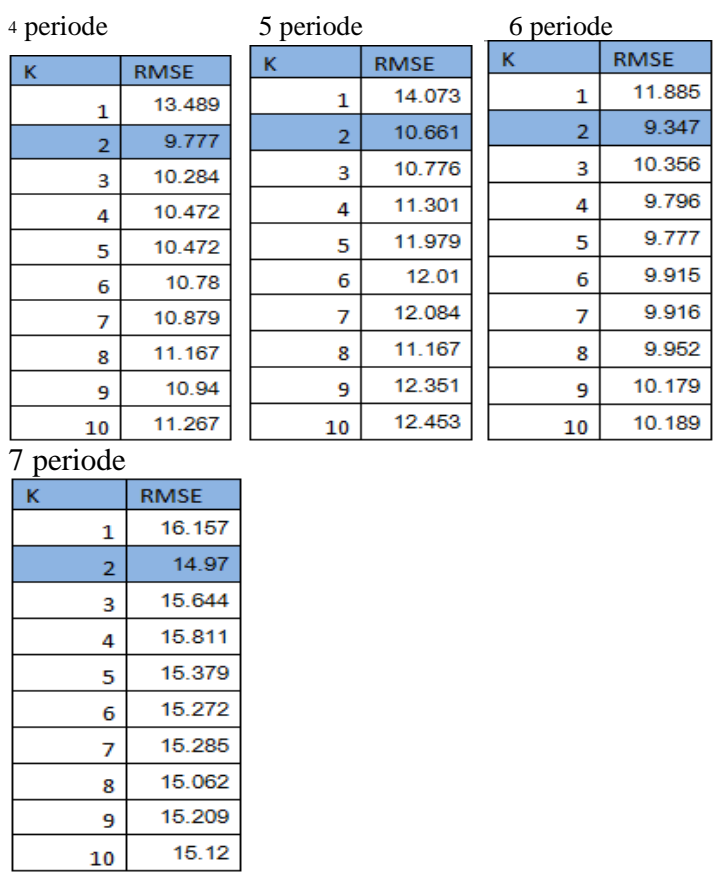

Berikut ini adalah rangkuman dari hasil uji coba arsitektur terbaik pada setiap periode.

\begin{tabular}{|l|r|r|}
\hline PERIODE & K & RMSE \\
\hline $\mathrm{XT} 1$ & 2 & 8.511 \\
\hline $\mathrm{XT} 2$ & 10 & 9.57 \\
\hline $\mathrm{XT} 3$ & 9 & 10.7 \\
\hline $\mathrm{XT} 4$ & 2 & 9.777 \\
\hline $\mathrm{XT} 5$ & 2 & 10.661 \\
\hline $\mathrm{XT} 6$ & 2 & 9.347 \\
\hline $\mathrm{XT} 7$ & 2 & 14.97 \\
\hline
\end{tabular}

\section{KESIMPULAN}

Prediksi jalur lalu lintas jangka pendek digerbang tol Manyaran Semarang yang di mulai dari tahun 2010-2017 dengan menggunakan metode $K$-Nearest Neighbor 
(K-NN) dengan hasil prediksi tahun 2018 angka kenaikan pada bulan. Januari 949014 Februari 902284, Maret 845307, April 919796, Mei 970834, Juni 1377159, Juli 946759, Agustus 897521, September 939153, Oktober 921456, November 931507, Desember 946750. dan mengunakan aplikasi Microsoft Excel dan menggunakan aplikasi Rapid Miner dapat menghasilkan nilai RMSE yang cukup rendah dengan menggunakan $K$-Flod validation sebanyak 10 kali dengan nilai RMSE terendah pada period ke enam/ xt 6 dengan nilai $\mathrm{k}=4$ menghasilkan nilai error yang rendah yaitu 7.924

\section{DAFTAR PUSTAKA}

Erisa Adyati Rahmasari. "Peningkatan Akurasi Menggunakan Neural Network Dan Particle Swarm Optimization (Pso) Dalam Prediksi Arus Lalu Lintas Jangak Pendek. Pasca Sarjana Universitas Dian Nuswantoro Semarang, 2015.

Ida Fitroh ," Metode K-Nearest Neighbor Berbasis Particle Swarm Optimization untuk peramalan kepadatan arus lalu lintas" Pasca Sarjana Universitas Dian Nuswantoro Semarang, 2015.

Lun Zhang, Qiuchen Liu, Wenchen Yang, Nai Wei, Decun Dong An, "Improved K-nearest Neighbor Model for Shortterm Traffic Flow Prediction", 13th COTA International Conference of Transportation Professionals (CICTP 2013), 2013.

Manual Kapasitas Jalan Indonesia (MKJI).: Dirjen Bina Marga, 1997.

Undang-undang republik Indonesia No. 14 Lalu Lintas dan Angkutan Jalan. Indonesia: Presiden Republik Indonesia, 1992. 